\title{
Las terceras fuerzas
}

No cabe duda alguna de que el tema de la eficacia de los partidos políticos en cuanto a su función de intermediarios entre las demandas de la sociedad y las respuestas del entramado institucional estatal a las mismas, ocupa en el país un espacio importante en el debate político. Los ciudadanos salvadoreños, en su mayoría, no se sienten representados por los políticos de profesión. Diferentes encuestas de opinión pública revelan el divorcio existente entre electores y elegidos. El desprestigio generalizado que conoce la clase política actual no tiene parangón en la historia reciente del país. La corrupción endémica y el nepotismo han alcanzado niveles insospechados. Por esa situación, crece la apatía de la población en cuanto a su participación en eventos políticos.

Para gran parte de los salvadoreños, los partidos políticos son reductos de dinosaurios que buscan perpetuarse en el poder. En esos institutos políticos, los intereses mezquinos priman sobre cualquier visión de nación. En consecuencia, el abstencionismo electoral aparece como una respuesta suscitada por el comportamiento inescrupuloso de los elegidos. De hecho, se ha señalado reiteradamente una disminución constante y creciente en lo que a participación electoral ciudadana se refiere. Los sondeos públicos revelan que el abstencionismo se debe a la poca confianza que se tiene en los políticos. Algunos partidos no llegan tan siquiera a la movilización de sus votos duros.

Ante el creciente descrédito de la clase política, se han alzado voces que reclaman un cierto código de conducta para los políticos. Los responsables de los partidos políticos multiplican declaraciones haciendo su mea culpa. Unos han llegado a confesarse de confrontativos; actitud que proponen deponer para favorecer la imagen de su partido y de los políticos, en general. Pero más allá de declaraciones coyunturales, sin pizca de convencimiento, han visto el día varios movimientos de ciudadanos que pretenden rescatar la política de los políticos corruptos. Son los conocidos movimientos de los ciudadanos independientes y los movimientos de centro o de terceras fuerzas. Estas últimas, además de exigir una cierta ética para la política, buscan quebrar el modelo bipartidista al que responsabilizan de la apatía de los electores. Son los casos del recién estructurado Centro Democrático Unido (CDU) y los esfuerzos de unificación de los partidos demócrata cristianos. El análisis del alcance y de la posibilidad de triunfo de estos movimientos, llamados de centro, es lo que se propone el siguiente comentario.

Una Coordinadora Demócrata Cristiana que se formó en días pasados pretende unir a movimientos políticos de una misma tendencia: Partido Demócrata Cristiano (PDC), Unificación Cristiana Democrática (UCD) y el Movimiento Acción Social Cristiana (MASC) de inspiración social cristiana, cuyo objetivo es luchar contra los problemas que aquejan a la sociedad y presentar una alternativa viable a la población que, además de superar la "polarización política partidarista extrema que vive El Salvador" - como caracterizan al momento actual del país-, ayude a solucionar los problemas más cruciales de la vida nacional y a recuperar la confianza en los políticos.

En la misma línea, el Centro Democrático Unido lleva varios intentos de unificación de partidos de tendencias centro izquierda. Una primera ini- 
ciativa de formación del CDU empezó en 1999. Por entonces, Rubén Zamora, ex candidato a la presidencia, se perfiló como el líder indiscutible de esta nueva formación política de coalición, cuyo objetivo era iniciar el proyecto de la tercera fuerza, que debería establecer un equilibrio entre Arena y el FMLN. Y, efectivamente, la gente pareció aceptar las propuestas. En las elecciones de 1999, el Centro Democrático Unido se situó como tercera fuerza electoral, con relativa facilidad, con una cantidad considerable de votos a nivel nacional. Sin embargo, a menos de dos años de haberse constituido como partido político, sobrevino la debacle en su interior. En las elecciones del 2000, no alcanzó el porcentaje requerido por ley para sobrevivir como coalición de partidos. El Tribunal Supremo Electoral procedió a la cancelación de los partidos integrantes de la coalición CDU. De esa manera, muere el primer movimiento político de centro que había hecho del tema de la polarización bipartidista su caballo de batalla y que pretendía aprovechar una imagen conciliadora, más allá de las antípodas FMLN y Arena.

Sin embargo, el intento del Centro Democrático Unido de consignar una tercera fuerza que fuera capaz de desbancar a Arena y al FMLN, se antojaba como la alternativa más realista en la coyuntura política del momento. Pero, ¿cómo reaccionan los salvadoreños ante la idea de que se formen terceras fuerzas políticas? ¿A qué se debió el fracaso del CDU? ¿Qué signos de la actual situación política podrían ayudar a fortalecer el movimiento de tercera fuerza? ¿Cómo detener el creciente descrédito de los partidos y líderes políticos? ¿Fue la excesiva polarización lo que podría explicar el fracaso del CDU en la simpatía popular? Son algunas preguntas sobre las cuales exploraremos algunas respuestas en la siguiente reflexión.

En primer lugar, se puede apuntar a la identidad de los partidos que conformaban la coalición, la falta de trayectoria política de algunos y la dependencia de un personaje. Para algunos, la unión entre la Convergencia Democrática (CD), el Partido Demócrata (PD), el Movimiento de Unificación Demócrata Cristiano (MUDC), el Partido Popular Laborista (PPL) y los proyectos políticos Fe y Esperanza, no era algo esperado por la falta de un punto de coincidencia clara entre estas formaciones políticas'. De ahí su excesiva dependencia de una figura carismática - como la de Rubén Zamora, conocido ex candidato de la coalición FMLN-CD a la presidencia, en las elecciones de 1994 , propia de las elecciones presidenciales que, en cambio, no suele despertar el mismo entusiasmo en las elecciones para diputados y alcaldes.

Por otra parte, se podría analizar la representatividad e idoneidad de los representantes de los movimientos políticos en formación o de los partidos ya constituidos que conformaron el proyecto CDU y ver en el comportamiento de sus dirigentes una posible causa del fracaso de este proyecto político. En ese contexto, podría resultar provechoso tomar en cuenta las acusaciones contra Rubén $\mathrm{Za}$ mora, en cuanto a posibles favores recibidos por parte de Arena.

Sin embargo, aunque en el análisis del motivo de la sorprendente pérdida de apoyo popular de un movimiento que se perfilaba con éxito un digno representante de la tercera fuerza, no se pueden despreciar esos elementos; los hechos sugieren que hay otros que podrían estar a la base de esta realidad y que de alguna manera podrían tener el mismo efecto en proyectos futuros de movimiento de centro. Para analizar los posibles alcances de los nuevos proyectos políticos - Centro Democrático Unido y la unificación de los partidos demócrata cristianos- es necesario tomar en cuenta esos elementos.

Por otro lado, el panorama político sugiere que una respuesta a las preguntas antes señaladas no se puede deslindar de la discusión en torno al tema del bipartidismo o multipartidismo ${ }^{2}$. En la medida en que se dilucide este tema se podrá entender de manera más nítida lo que está sucediendo actualmente en el país. Los grupos que se reclaman de tercera fuerza reconocen en principio que el FMLN y Arena propician un escenario bipartidista que fomenta una polarización que es necesario romper, en beneficio de los intereses de la población.

En un estudio reciente de Álvaro Artiga. sobre las elecciones y las posturas de los partidos nacio-

1. Ver “Triunfo electoral de ARENA: ¿cinco años de lo mismo?”, ECA 604-605, febrero-marzo, 1999, p. 183.

2. Ver "A propósito de la polarización”, ECA 6I8, abril, 2000, la discusión de Luis Gonzálcz sobrc la polarización política y el bipartidsimo o multipartidismo.

3. Ver Álvaro Artiga-González, “Electores, partidos y la caja de Pandora”, ECA 617, marzo, 2000, pp. $267-289$. 
nales, se sostiene que no es del todo apropiado hablar de un bipartidismo a nivel nacional. Artiga plantea que si bien a nivel nacional, en elecciones legislativas y presidenciales, se puede hablar de un bipartidismo, la realidad se presenta de manera diferente respecto a las elecciones municipales. En esta esfera, el investigador aboga por un multipartidismo, dadas las características de los resultados obtenidos. "Con estas consideraciones creo que hablar de bipartidismo, sin más, es sumamente simplista. [...] Si hemos de ser rigurosos en el análisis científico, deberíamos considerar que para cada tipo de elección y para cada circunscripción electoral tenemos un sistema de partidos específico. Ignorar este detalle contribuye a pasar por alto la posibilidad de una reforma electoral, que permita la existencia de partidos políticos departamentales y municipales"4. Aunque el tema de la regionalidad de las elecciones y de los partidos no nos ocupa en esta reflexión, sí es importante retomar la discusión en torno al tema del bipartidismo o multipartidismo.

Siendo así las cosas, es insuficiente atribuir el fracaso reciente del Centro Democrático Unido a la polarización bipartidista, como algunos parecen sugerir, sino que habría que tomar en cuenta que los malos resultados se dieron precisamente en elecciones municipales y legislativas que -en opinión de Álvaro Artiga - sugieren la existencia de un multipartidismo. Por lo tanto, el fracaso se debe más a su capacidad de influencia en los municipios, que significa, además, que no logró incidir en la gente por medio de propuestas concretas. De esta manera, se podría inferir que los municipios constituyen el escenario donde los movimientos "terceristas" en formación podrían iniciar su ensayo, si es que aspiran a romper el hechizo de la polarización.

En principio, con el presupuesto de que la población no ve con simpatía el hecho de la polarización entre los dos partidos más grandes, se puede pensar que los ciudadanos acogerían favorablemente al movimiento de tercera fuerza, que devuelva la credibilidad a la política. En este sentido, más que tomar posición contra Arena y el FMLN, los movimientos de tercera fuerza tienen que demostrar con hechos que tienen capacidad para seducir al pueblo con ofertas coherentes, prácticas y novedosas. Esta argumentación parece

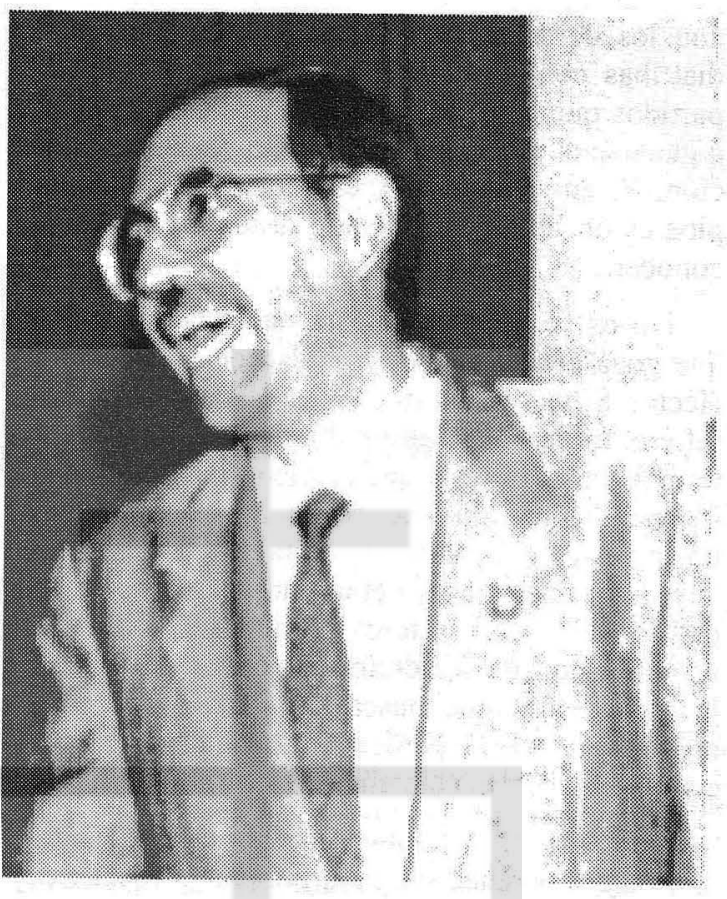

explicar bastante bien la situación que se dio en torno al CDU en sus inicios. Gran parte de la población acogió favorablemente la idea. Sin embargo, momentos después, dicho partido perdió la fuerza que lo empujaba. Hay que ver, en este fracaso, su incapacidad para seguir manteniendo la esperanza de la población. Invirtieron más tiempo en la crítica a los partidos grandes, principalmente al FMLN, que en construir realmente un bloque que superara los problemas encontrados.

De ahí las razones para que el fortalecimiento de un movimiento de tercera fuerza encuentre su legitimación, quizá no porque la coyuntura esté demandando el surgimiento de nuevos partidos políticos - como lo sugieren algunos líderes de nuevos movimientos-, sino porque el FMLN y Arena ya no representan la aspiración de los salvadoreños. Al contrario, lo que sí parece importante es que los partidos políticos existentes se democraticen y que la institucionalización de los mismos dé cauce normal a las luchas por controlar el poder dentro de los institutos políticos. De ahí que la justificación de los movimientos "terceristas" tenga que ver con la incapacidad de los partidos tradicionales de conciliar los intereses de sus cúpulas

4. Ibid., p. 273. 
con los de sus electores. En vez de perderse en diatribas contra los partidos grandes, los nuevos partidos que se forman deberían dedicar el tiempo a ganarse el respeto y la confiabilidad de la población. Y, en este sentido, el trabajo en los municipios es un lugar privilegiado desde donde darse a conocer.

No es ya un secreto para nadie la simpatía de que goza el alcalde de la ciudad de San Salvador, Héctor Silva, en lo que a aceptación popular se refiere. Silva no es, en modo alguno, independiente; por tanto, la tesis que sostiene que hay que ser independiente para tener buena aceptación popular no se sostiene. El alcalde capitalino debe su popularidad al buen trabajo emprendido, a su sensibilidad social con los sectores marginados de la capital, a la eficiencia de su administración y a su rechazo a la politiquería, que busca estar bien con todo cl mundo para luego perderse en nulidades y no hacer nada que valga la pena en el cargo confiado.

Por lo tanto, cualquier partido político o líder que quiera obtener simpatía popular y escalar peldaños para romper el pretendido bipartidismo polarizado que impera a nivel nacional y que parece romperse a nivel local; cualquier partido que quiere trabajar en este sentido, debería comenzar por los municipios. La actual coyuntura nacional parece invitar a trabajar en este sentido a la hora de plantear la solución a los problemas que enfrentan los políticos y los partidos en general. Los partidos políticos no gozan de simpatía popular por arte de magia o porque sus dirigentes sean empresarios exitosos, como lo proyecta algún sector nacional, sino porque, a estas alturas, los políticos no han sabido dar respuestas concretas a las demandas de la población. Los partidos políticos han sido receptáculos de intereses de una minoría y no de los intereses de sus votantes. Por eso, el desencanto nacional; desde ahí se debe trabajar.

Tampoco el problema es ideológico como algunos pudieran suponer. Para el caso, hay que decir que no hay evidencias de que el electorado nacional esté interesado en la denominación ideoló- gica de los partidos. En este sentido, que se autodenomine de centro izquierda o demócrata cristiano no parece ser lo determinante. A estas alturas están desprestigiados todos por igual. Al contrario, en estas denominaciones parece existir mayor riesgo de luchas intestinas por cuotas de poder que favorecen los intereses mezquinos de un grupo bien determinado.

Por lo tanto, una tercera fuerza política o quien quiera trabajar en la recuperación de la confianza de la población en la clase política debe dedicarse a estos temas. Es clave evitar el clientelismo estatal. Es lo que el primer intento del Centro Democrático Unido no logró; de ahí su caída estrepitosa en las elecciones pasadas. Tampoco se perfiló en las alcaldías que gobernaba como una alternativa clara para una nueva manera de hacer las cosas en El Salvador. A pesar del apoyo de la Convergencia Democrática a Héctor Silva, político exitoso en la alcaldía de San Salvador, éste es visto por la población como miembro del FMLN.

Así, las nuevas agrupaciones que busquen establecer una tercera fuerza capaz de responder a las quejas de la población frente a los partidos políticos tienen mucho que hacer. En primer lugar, las simpatías no se logran tan sólo basándose en la figura de un dirigente. En segundo lugar, el escenario político nacional hace de las alcaldías el lugar de prueba de los personajes y partidos políticos. A ello se debe el repunte del FMLN y del alcalde Héctor Silva al frente de la comuna capitalina. Y, finalmente, no se pueden crear partidos nuevos con el mismo formato de los partidos que se quieren desplazar. Los partidos tienen que dar señales de democratización interna y de haber superado la idea de que sus dirigentes buscan el lucro desde una posición de poder. Por lo tanto, si las nuevas agrupaciones no trabajan en esta dirección esperada por el pueblo, terminarán en un fracaso, que no sólo será para ellos, sino también para la población, cuyo desencanto aumentará, pues seguirá creyendo que no hay manera de librar al país de los políticos corruptos.

\section{R. Joseph}

